\title{
Comparison of Ropivacaine $0.2 \%$ Alone and in Combination with Fentanyl for Caudal Anesthesia in Paediatric Patients
}

\author{
Dr. Tejinderpal Kaur Grewal ${ }^{* 1}$, Dr. Balwinder Kaur ${ }^{1}$, Dr. Parmod Kumar ${ }^{2}$, Dr. Sukhdeep Kaur ${ }^{3}$ \\ ${ }^{1}$ Professor, ${ }^{2}$ Professor \& Head, ${ }^{3}$ Junior Resident, \\ Department of Anaesthesia, Goverment Medical College, Patiala
}

Address of Correspondence - Dr. Tejinderpal Kaur Grewal

Received 14 January 2019;

Accepted 30 January 2019;

Published 02 February 2019

\begin{abstract}
Background: Caudal epidural block is one of the most common regional techniques in paediatric anesthesia. It is safe, easy to perform and has been found to be very effective in children undergoing infra-umbilical surgeries .Ropivacaine produces differential neuraxial blockade with less motor block and reduced cardiovascular toxicity. Various adjuvants are added to increase the duration of action of local anesthetics. The aim of our study was to evaluate the action of fentanyl on duration of postoperative analgesia when added as an adjunct to ropivacaine in paediatric population of age 3-8 years undergoing infraumbilical surgeries. Methods: A double blind, prospective, comparative and randomized study was conducted on 50 paediatric patients undergoing elective infraumbilical surgery. Patients were randomly divided into two groups of 25 each by simple envelope method. After securing airway, caudal anaesthesia was given. Group R received $0.2 \%$ ropivacaine $0.5 \mathrm{ml} / \mathrm{kg}$ and Group RF received $0.2 \%$ ropivacaine $0.5 \mathrm{ml} / \mathrm{kg}$ with fentanyl $0.5 \mathrm{mcg} / \mathrm{kg}$. Post-operative pain was assessed by face, legs, activity, cry and consolability pain assessment scale for $24 \mathrm{~h}$. Duration of motor blockade and side effects were noted. The hemodynamics, duration of post-operative analgesia and number of rescue analgesia needed was noted and analyzed statistically. Results: Mean duration of analgesia in ropivacaine group is $441.60 \pm 102.29$ minutes $(7.35 \mathrm{hrs})$ and in ropivacaine fentanyl group was $892 \pm 313.84$ (14.86hrs). Statistically the difference was highly significant as $\mathrm{p}$ value was $<0.001$. Conclusions: Fentanyl as an adjuvant to ropivacaine for caudal block has significantly improved analgesic efficacy and increased the duration of post-operative analgesia in children undergoing infraumbilical surgery.
\end{abstract}

Keywords: Caudal, Fentanyl, Paediatric, Post-operative analgesia, Ropivacaine

\section{Introduction}

Pain is defined by the international association for study of pain as an "unpleasant sensory and emotional experience associated with actual or potential tissue damage or described in terms of such damage". [1]

Caudal epidural block is one of the most common regional techniques in paediatric anesthesia. It is safe, easy to perform and has been found to be very effective in children, especially in infraumbilical surgeries. It provides good post-operative analgesia and rapid recovery from anesthesia. ${ }^{[2]}$

Caudal anesthesia can reduce the amount of inhaled and intravenous anesthetic required, attenuate the stress response to surgery. Other advantages of caudal block are early ambulation and decreased risk of chest infection, decreased postoperative analgesic requirements and early discharge. ${ }^{[3]}$
Ropivacaine was introduced into clinical practice in 1996 and has consistently demonstrated an improved safety profile over bupivacaine with a reduced CNS and cardiotoxic potential. Recently ropivacaine is gaining importance as a local anesthetic to be used in caudal blocks. ${ }^{[4]}$

The addition of an adjuvant not only increases the effectiveness of a local anesthetic by prolonging and intensifying the sensory blockade but also causes reduction in dose of local anesthetic agents.

Fentanyl is a synthetic, highly selective opioid agonist that works mainly at the mu-opioid receptor, with some activity at the delta and kappa receptors. Fentanyl is highly potent being 100 to 300 fold more potent than morphine. Its high lipophilicity allows rapid penetration into CNS structures. ${ }^{[5]}$ 
The present study was conducted to evaluate the action of fentanyl on duration of postoperative analgesia when added as an adjunct to ropivacaine in paediatric population of age 3-8 years undergoing infraumbilical surgeries.

\section{Methods}

The present prospective, randomised, double blind study was conducted in Department of Anesthesia, Rajindra Hospital/Government Medical College, Patiala, after obtaining the approval from Institute's Ethical Committee. The study was conducted on 50 paediatric patients of either sex aged between 3 to 8 years of age belonging to ASA-I \& II undergoing infraumbilical surgeries. The exclusion criteria included parent's refusal, history of developmental delay or delayed milestones, mental retardation ,child with suspected coagulopathy or bleeding diathesis, body weight $>30 \mathrm{~kg}$ and local sepsis at the site of puncture.

After obtaining consent from parents or guardians children were randomly divided into two groups with 25 children in each group. Randomization was done by simple envelope method.

Group R - received $0.2 \%$ ropivacaine $0.5 \mathrm{ml} / \mathrm{kg}$.

Group RF - received $0.2 \%$ ropivacaine $0.5 \mathrm{ml} / \mathrm{kg}$ with fentanyl $0.5 \mathrm{mcg} / \mathrm{kg}$.

\section{SAMPLE SIZE}

Sample size was estimated based on pilot study, we see that mean difference in heart rate in two groups was 0.18 with common SD of 0.22 . With this our sample size $n=24$ per group at a power of $80 \%$ with $\mathrm{z}$ value of 1.96 at $5 \%$ level of significance. For possible dropouts, it was decided to include 25 patients per group

\section{TECHNIQUE}

Patients were kept fasting for 4- 6 hours before surgery depending upon age. On the day of surgery premedication was given orally with syrup midazolam $0.5 \mathrm{mg} / \mathrm{kg} 30-45$ minutes prior to induction. An intravenous line was established and inj. glycopyrrolate 0.005 $0.01 \mathrm{mg} / \mathrm{kg}$ and inj. ondansetron $0.15 \mathrm{mg} / \mathrm{kg}$ were administered. Induction was done with either $2-3 \mathrm{mg} / \mathrm{kg}$ of propofol or with halothane/sevoflurane in $100 \%$ oxygen. Airway was secured with appropriate sizes of endotracheal tube or laryngeal mask airway and anesthesia was maintained with O2, N2O and halothane/sevoflurane. Monitoring of ECG, blood pressure, Spo2and heart rate was done.

After securing airway, patient was placed in the lateral decubitus position and vitals and adequacy of respiration were checked. Back was cleaned with antiseptic solution and draped. Sacral hiatus was identified under aseptic conditions. 22G hypodermic needle was advanced at a $45^{\circ}$ angle cephalad until a pop is felt as the needle pierces the sacrococcygeal ligament. The angle of the needle was then flattened and advanced to enter sacral hiatus. Caudal epidural space was identified by using standard loss of resistance technique. The drugs were given in caudal block according to the groups after negative aspiration for blood and cerebrospinal fluid.

Group R - received $0.2 \%$ ropivacaine $0.5 \mathrm{ml} / \mathrm{kg}$.

Group RF - received $0.2 \%$ ropivacaine $0.5 \mathrm{ml} / \mathrm{kg}$ with fentanyl $0.5 \mathrm{mcg} / \mathrm{kg}$.

The site of injection was dressed and the patient was turned supine. After 15 minutes of the procedure surgery was allowed to proceed.

In our study the haemodynamic parameters SpO2, HR, SBP,DBP,MAP and RR were monitored during preoperative period and then every 5 minutes intraoperatively upto half an hour and then every 10 mins upto completion of surgery.

Postoperatively hemodynamics, pain score, motor blockade, sedation score and side effects were calculated every 15 min till 2 $\mathrm{h}$, then every 2 hourly till $12 \mathrm{~h}$ and then at $24^{\text {th }} \mathrm{h}$. FLACC scale ${ }^{[6]}$ (Table no.1) was used for assesement of pain. The duration of analgesia was defined as the time from caudal placement of drug to the first recording of a FLACC scale $\geq 4$. Rescue analgesia had been provided with syrup paracetamol10mg/kg whenever the pain score was $\geq 4$. The number of rescue analgesia required within 24 hours was noted.

The degree of motor blockade was assessed by Bromage scale. Bromage 0 - Full flexion of knees and feet possible, able to lift extended legs.Bromage 1 - Unable to lift extended legs, but able to flex knees and feet. Bromage 2 - Unable to flex knees but flexion of feet possible. Bromage 3 - Unable to move legs and feet at all. Sedation Score ${ }^{[7]}$ had been assessed as 0 -arousable, 1 - arousable to voice,2-arousable to pain and 3- unarousable.

Table 1

\begin{tabular}{|l|l|l|l|}
\hline \multicolumn{1}{|c|}{ FLACC Scale } & \multicolumn{1}{c|}{$\mathbf{1}$} \\
\hline \multicolumn{1}{|c|}{ Parameter } & \multicolumn{1}{|c|}{$\mathbf{2}$} \\
\hline Face & No expression & Occasional grimace & Frequent to constant quivering chin. \\
\hline Legs & Normal position or relaxed & Uneasy, restless, tense & Kicking or legs drawn up \\
\hline Activity & Lying quiet & Squirming, shifting back and forth, tense & Arched, rigid or jerking \\
\hline Cry & No cry & Moans or whimpers & Crying steadily \\
\hline Consolability & Content, relaxed & Reassurance, hugging & Difficulty to console \\
\hline
\end{tabular}

Statistical Analysis: Analysis was conducted using IBMM SPSS statistics (version 22.0). Numerical data was expressed as mean and standard deviation and statistically analysis was done using the independent $t$ test to compare the two groups. For skewed

\section{Results}

A total of 50 paediatric patients of age group 3-8 years were enrolled in the study. Caudal block was successful in all the patients. The demographic data of the two groups did not differ (Table 2). There was no significant difference in the hemodynamic parameters between the two groups. There was no case of motor data/scores Mann-Whitney U-test was used. Gender was compared using Chi square test. The $\mathrm{p}$ value of $<0.05$ was considered statistically significant and the $\mathrm{p}$ value of $<0.001$ was considered statistically highly significant.

blockade after the surgery. Vomiting was noticed in one patient in Group R and in 3 patients in group RF. No other side effects were noticed in either group (Table 3). Comparison of FLACC pain score among Group R and Group RF was analyzed (Table 4). The mean FLACC reached $\geq 4$ in group $R$ at 6 hours and at 12 hours in group RF.As shown in table 5 mean duration of analgesia in ropivacaine group is $441.60 \pm 102.29$ minutes $(7.35 \mathrm{hrs})$ and in 
ropivacaine fentanyl group was $892 \pm 313.84$ (14.86hrs) [p-value $(<0.001)]$. Mean no. of rescue analgesia that was needed in group
$\mathrm{R}$ was $1.56 \pm 0.50$ and in group RF was $0.84 \pm 0.37$.

Table 2: Demographic Data

\begin{tabular}{|l|c|c|c|}
\hline Data & Group R & Group Rf & P Value \\
\hline Age (yrs.) & $5.04 \pm 1.42$ & $4.64 \pm 1.49$ & 0.339 \\
\hline Weight (kgs) & $17.24 \pm 4.90$ & $15.48 \pm 3.25$ & 0.141 \\
\hline Sex & & & \\
\hline Sex (\%) & & & \\
Male & 88 & 16 & 0.684 \\
Female & 12 & $45.2 \pm 11.8$ & \\
\hline Duration of surgery(mins) & $45.2 \pm 9.94$ & & 0.911 \\
\hline
\end{tabular}

Table 3: Complications

\begin{tabular}{|l|c|c|c|}
\hline Complication & Group R & Group RF & P value \\
\hline Bradycardia & 0 & 0 & - \\
\hline Hypotension & 0 & 0 & - \\
\hline Retching & 0 & 0 & - \\
\hline Vomiting & 1 & 3 & 0.297 \\
\hline Respiratory Depression & 0 & 0 & - \\
\hline Urinary Retention & 0 & 0 & - \\
\hline
\end{tabular}

Table 4: FLACC score (Mean \pm SD) during postoperative period in two groups

\begin{tabular}{|c|c|c|c|}
\hline TIME & Group R & Group RF & P Value \\
\hline 0 mins & $0.08 \pm 0.27$ & $0.00 \pm 0.00$ & 0.153 \\
\hline $15 \mathrm{mins}$ & $0.12 \pm 0.33$ & $0.00 \pm 0.00$ & 0.077 \\
\hline $30 \mathrm{mins}$ & $0.24 \pm 0.52$ & $0.00 \pm 0.00$ & 0.020 \\
\hline $45 \mathrm{mins}$ & $0.64 \pm 0.86$ & $0.04 \pm 0.20$ & 0.001 \\
\hline $60 \mathrm{mins}$ & $0.92 \pm 0.86$ & $0.04 \pm 0.20$ & $<0.001$ \\
\hline $75 \mathrm{mins}$ & $1.16 \pm 0.80$ & $0.04 \pm 0.20$ & $<.001$ \\
\hline $90 \mathrm{mins}$ & $1.36 \pm 1.15$ & $0.16 \pm 0.37$ & $<0.001$ \\
\hline $105 \mathrm{mins}$ & $1.36 \pm 0.90$ & $0.48 \pm 0.50$ & $<0.001$ \\
\hline $120 \mathrm{mins}$ & $1.96 \pm 0.93$ & $0.76 \pm 0.66$ & $<0.001$ \\
\hline $4 \mathrm{hrs}$ & $1.84 \pm 1.06$ & $0.28 \pm 0.61$ & $<0.001$ \\
\hline $6 \mathrm{hrs}$ & $3.16 \pm 1.49$ & $0.72 \pm 0.61$ & $<0.001$ \\
\hline $8 \mathrm{hrs}$ & $2.48 \pm 1.73$ & $0.76 \pm 0.59$ & $<0.001$ \\
\hline $10 \mathrm{hrs}$ & $1.40 \pm 1.89$ & $2.72 \pm 0.45$ & $<0.001$ \\
\hline $12 \mathrm{hrs}$ & $2.28 \pm 0.84$ & $3.28 \pm 1.30$ & 0.024 \\
\hline
\end{tabular}

Table 5: Mean duration of analgesia (Minutes) and mean number of rescue analgesia in the postoperative period

\begin{tabular}{|l|c|c|c|}
\hline & Group R & Group RF & P value \\
\hline Mean duration of analgesia (mins) & $441.60 \pm 102.29$ & $892.80 \pm 313.84$ & $<0.001$ \\
\hline Mean No. of doses of rescue analgesia neeed & $1.56 \pm 0.50$ & $0.84 \pm 0.37$ & $<0.001$ \\
\hline
\end{tabular}

\section{Discussion}

Paediatric regional anesthesia has attained wide use internationally because of its efficacy and safety. The regional anesthetic techniques significantly decrease the postoperative pain and systemic analgesic requirements. Caudal epidural analgesia is most common regional anesthesia technique for providing anesthesia and analgesia in children undergoing infra umbilical surgeries. The aim of the present study was to evaluate the efficacy of fentanyl in prolonging the analgesic duration when given along with ropivacaine in caudal block for paediatric postoperative analgesia.

The two groups were comparable in terms of age, weight, sex distribution \& duration of surgery. In our study all the haemodynamic parameters were comparable at all time intervals throughout the study.
Gupta et al ${ }^{[8]}$ in 2014 compared ropivacaine alone and ropivacaine with fentanyl in perineal and subumbilical surgeries and concluded that there was no significant haemodynamic instability observed in either group throughout the study period.

Senugupta et $\mathrm{al}^{[9]}$ in 2015 compared caudal epidural ropivacaine with fentanyl and bupivacaine for paediatric postoperative analgesiain children posted for infraumbilical surgeries and found that there was no significant differences in the haemodynamic parameters between two groups.

The result of present study was in agreement with Gupta et a ${ }^{[8]}$ and Senugupta et al. ${ }^{[9]}$

\section{Pain scores}

Anand et $\mathrm{al}^{[10]}$ in 2011 conducted a study to compare the effects of caudal dexmedetomidine combined with ropivacaine to provide postoperative analgesia in children and assessed duration of 
analgesia by using pain score (FLACC Scale>4 ). The study concluded that pain score was 4 at 6thhour in 20 out of 30 children in ropivacaine group.

Gupta et a ${ }^{[8]}$ in 2014 conducted a study to compare fentanyl with ropivacaine and ropivacaine alone for caudal analgesia in paediatric patients and observed that pain score pain score was $>4$ at $16 \mathrm{hrs}$ in ropivacaine group and it was $>4$ at $36 \mathrm{hrs}$ in ropivacaine fentanyl group.

In present study, the mean FLACC reached $\geq 4$ in group $R$ at 6 hours and at 12 hours in group RF.

Our results were in close agreement with the studies conducted by Anand et al ${ }^{[10]}$ and Gupta et al. ${ }^{[8]}$

\section{Duration of analgesia}

Bosenberg et $\mathrm{al}^{[11]}$ in 2002 observed duration of analgesia with caudal $0.1 \%$ ropivacaine, $0.2 \%$ ropivacaine and $0.3 \%$ ropivacaine to be about $3.3 \mathrm{hrs}$, $4.5 \mathrm{hrs}$ and $4.2 \mathrm{hrs}$ respectively. $0.1 \%$ ropivacaine was found to be less efficacious while with the use of $0.3 \%$ ropivacaine higher incidence of motor block was observed without any significant improvement in duration of analgesia.0.2\% ropivacaine provided satisfactory postoperative analgesia after elective inguinal surgery. So we used $0.2 \%$ ropivacaine in present study.

Gupta et al ${ }^{[8]}$ in 2014 conducted a study to compare fentanyl with ropivacaine and ropivacaine alone for caudal analgesia and found that duration of analgesia in ropivacaine fentanyl group was $16-$ $20 \mathrm{hrs}$ more than ropivacaine alone group.

Shukla et $\mathrm{al}^{[12]}$ in 2016 compared caudal fentanyl and clonidine as an additive to roipvacaine in infraumbilical abdominal surgeries and observed that addition of fentanyl to ropivacaine provides prolonged postoperative analgesia in children.

Saini et al ${ }^{[13]}$ in 2016 conducted a study to compare the analgesic properties of clonidine and fentanyl as an analgesic adjunct in caudal epidural block with ropivacaine in children and found that mean duration of analgesia in fentanyl ropivacaine group was $708 \pm 54.08$ minutes(11.8hrs), which was similar to findings in present study.

In present study mean duration of analgesia in ropivacaine group is $441.60 \pm 102.29$ minutes $(7.35 \mathrm{hrs})$ and in ropivacaine fentanyl group was $892 \pm 313.84$ (14.86hrs).Thus fentanyl prolongs duration of analgesia when added as an adjunct to ropivacaine.

The result of present study were in close agreement with the above studies conducted by Bosenberg et al, ${ }^{[11]}$ Gupta et al, ${ }^{[8]}$ Shulka et al. ${ }^{[12]}$ and Saini et al. ${ }^{[13]}$

In contrast to forementioned studies, there was few studies where results are contrary to present study.

Kawaraguchi et $\mathrm{al}^{[14]}$ in 2006 conducted a study to evaluate whether the addition of fentanyl to ropivacaine prolonged the duration of analgesia after a single shot caudal block and concluded that the addition of fentanyl to ropivacaine $0.2 \%$ provides no further analgesic advantages over ropivacaine $0.2 \%$ alone. The probable explanation for this reason could be the difficulty in differentiating between pain response and agitation on emergence, especially in younger children. Pain score was assessed by using different scale from our study. Among the patients administered analgesics, there might be the one exhibiting agitations rather than pain complaint. Furthermore, type of surgical procedure is varied in the study.

Rao et $\mathrm{al}^{[15]}$ in 2017 conducted a study to compare ropivacaine $0.2 \%$ versus ropivacaine with fentanyl $1 \mathrm{mcg} / \mathrm{kg}$ versus ropivacaine $0.2 \%$ with neostigmine $2 \mathrm{mcg} / \mathrm{kg}$ as a single shot caudal block on post-operative analgesic effect in children and concluded that ropivacaine caused a prolongation of duration of analgesia, while a ropivacaine and fentanyl mixture did not cause any statistically significant increase in the duration of analgesia. The result is contrary to our study and the reason being that it was difficult to distinguish between sedation and analgesia in the study groups as a pain-free child is calm, comfortable or asleep. Other reason is that type of surgical procedures were varied. The intensity of post-operative pain may vary depending on the type of surgical procedure.

\section{Number of rescue analgesia needed}

Our study has found that the mean no. of rescue analgesia that was needed in group $\mathrm{R}$ was $1.56 \pm 0.50$ and in group $\mathrm{RF}$ was $0.84 \pm 0.37$.So no. of rescue analgesia needed in ropivacaine fentanyl group is less as compared to ropivacaine alone group.

Senugupta et $\mathrm{al}^{[9]}$ in 2006 observed that patients in ropivacaine fentanyl group required less doses of rescue analgesia as compared to bupivacaine fentanyl group.

The result of our study was in agreement with a study conducted by Senugupta et al. ${ }^{[9]}$

Gupta et al ${ }^{[8]}$ in 2014 conducted a study to compare fentanyl with ropivacaine and ropivacaine alone has also stated that there was no significant motor blockade in both the groups. In present study there was no significant motor blockage in both the groups in recovery room. So present study is in accordance to the literature and had no motor blockade.

\section{Sedation score}

In present study, the mean sedation score (SS) during postoperative period was comparable at all intervals in both groups. A study conducted by Kawaraguchi et $\mathrm{al}^{[14]}$ compared fentanyl with ropivacaine and ropivacaine alone and found that sedation score had no statistical difference between two groups which is in agreement with present study.

\section{Side effects}

In present study, the incidence of vomiting was $4 \%$ in group R and $12 \%$ in group RF. None of the patients in both groups develop bradycardia, hypotension, respiratory depression, retching and urinary retention.

Khatavkar et $\mathrm{al}^{[16]}$ in 2006 compared clonidine with fentanyl as an adjuvant with ropivacaine for caudal block and found that no patient had urinary retention, respiratory depression or any other complication.

Gupta et $\mathrm{al}^{[8]}$ in 2014 compared fentanyl with ropivacaine and ropivacaine alone for caudal analgesia in paediatric patients and reported that reported that 1 patient in ropivacaine group and 4 patients in ropivacaine fentanyl group had vomiting. No patient developed respiratory depression, bradycardia and hypotension 
The present study was in consistent with the studies done previously by Khatavkar et al ${ }^{[16]}$ and Gupta et al. ${ }^{[8]}$

\section{Conclusion}

The present study concluded that fentanyl is safe and effective adjuvants to ropivacaine when used in caudal anesthesia in paediatric patients undergoing infraumbilical surgery. Addition of fentanyl to ropivacaine prolongs the duration of analgesia and decreases the need of rescue analgesia in the postoperative period.

\section{Bibliography}

[1] Pain terms: a list with definitions and notes on usage. Recommended by the IASP subcommittee on taxonomy. Pain. 1979; 6: 249.

[2] Ganeshnavar A, Joshi C, Masur S, Hulkund SY. Comparison of dexmedetomidine and clonidine as adjuvants to $0.25 \%$ bupivacaine in paediatric caudal block for infraumbilical surgeries. Intl.Jclin. Diag.Res.2015;3 (4).

[3] Palkhiwla BB, Gajjar HR., Shah R. Study of caudal anesthesia with ropivacaine under sedation for infraumbilical surgery in paediatrics patients: NHL .Journal of Medical Sciences.2014; 3(1):37-40.

[4] McClellan KJ, Faulds D. Ropivacaine: an update of its use in regional anaesthesia. Drugs. 2000;60:1065-93.

[5] Henthorn TK, Liu Y, Mahapatro M, Ng KY.Active transport of fentanyl by the blood-brain barrier. J Pharmacol Exp Ther. 1999;289 (2):1084-9.

[6] Chakravarthy K, Anupuram LN, Cherukuri SK, Nalagandla SR, Konda RRM. Evaluation of caudal epidural with bupivacaine $0.20 \%$ versus ropivacaine $0.2 \%$ for post operative pain relief in paediatric lower abdominal surgeries. IOSR Journal of Dental and Medical Sciences.2016;15(1):47-51.

[7] Ali G, Kala N, Rather MA, Taj A, Maqbool S, Bhat KA. Comparative evaluation of caudal ropivacaine and ropivacaine with clonidine for postoperative analgesia in children. IOSR Journal of Dental and Medical Sciences. 2015;14(9): 50-54.
[8] Gupta P, Sharma P, Jethava D, Jethava DD.A comparison of Ropivacaine alone and in combination with fentanyl for caudal analgesia in pediatric patients. Journal of Dental and Medical Sciences.2014;13(11):1-4.

[9] Senugupta S, Mukherji S, Sheet J, Mandal A, Swaika S.Caudal-epidural bupivacaine versus ropivacaine with fentanyl for paediatric postoperative analgesia. Anesth Essays Res. 2015;9:208-12.

[10] Anand VG, Kannan M, Thavamani A, Bridgit MJ. Effects of dexmedetomidine added to caudal ropivacaine in pediatric lower abdominal surgeries. Indian $\mathbf{J}$ Anesth.2011; 55:340-6.

[11] Bosenberg A, Thomas J, Lopez T, Lybeck A, Huizar K , Larsson LE.The efficacy of caudal ropivacaine 1,2 and $3 \mathrm{mg} \cdot \mathrm{ml}-1$ for postoperative analgesia in children. Pediatric Anesthesia. 2002;12: 53-58.

[12] Shukla U, Prabhakar T, Malhotra K. Postoperative analgesia in children when using clonidine or fentanyl with ropivacaine given caudally. J Anesthesiol Clin Pharmacol. 2011;27:205-10.

[13] Saini S, Patodi V, Sethi SK, Jain N, Mathur P, Thada B. Comparison of caudal epidural clonidine with fentanyl as an adjuvant to ropivacaine $0.25 \%$ for postoperative analgesia in children undergoing various infraumbilical surgeries: A prospective randomized study. Ain-Shams J Anaesthesiol .2016;9:493-500.

[14] Kawaraguchi Y, Otomo T, Ota C, Uchida N, Taniguchi A , Inoue S. A prospective, double-blind, randomized trial of caudal block using ropivacaine $0.2 \%$ with or without fentanyl $1 \mu \mathrm{g} \mathrm{kg}-1$ in children.Br. J. Anaesth. 2006;97(6): 858-61.

[15] Rao MP, Babu SP, Saroj P. A randomised, double-blind, prospective study of caudal ropivacaine versus ropivacaine with fentanyl versus ropivacaine with neostigmine for combined epidural and general anaesthesia in children. J. Evolution Med. Dent. Sci. 2017;6(44):3459-68.

[16] Khatavkar SS, Lonkar SS, Panchal PB, Thatte WS, Nagendra S, Tewari D.The efficacy of ropivacainefentanyl versus ropivacaine-clonidine for pre-emptive caudal anesthesia in children. Anaesth Pain \& Intensive Care. 2016;20(1):54-8. 